\title{
Effects of Perhexiline on Hemodynamics in Anesthetized Open-Chest Dogs
}

\author{
Hiroshi Ono, M.D., Naoki O'Hara, B.S., \\ and Koroku Hashimoto, M.D.
}

\section{SUMmary}

Cardiohemodynamic effects of perhexiline were investigated in anesthetized open-chest dogs, measuring blood flow rates of the pulmonary artery (PAF), superior and inferior venae cavae (SVCF and IVCF), right atrial pressure (RAP), systemic blood pressure (SBP), and heart rate (HR). Sum of SVCF and IVCF was interpreted as venous return (VR). Perhexiline, $0.3-3 \mathrm{mg} / \mathrm{Kg}$, injected intravenously over $2 \mathrm{~min}$ caused dosedependent increases in PAF, VR, and RAP, followed by decreases in PAF and VR at higher doses. SBP and HR were depressed with perhexiline dose-dependently. Verapamil, 0.03-0.3 mg/Kg, also increased PAF, VR, and RAP to a lesser extent than perhexiline. Verapamil decreased these variables except RAP more markedly than perhexiline. Treatment with propranolol $(1 \mathrm{mg} / \mathrm{Kg})$ and phentolamine $(1 \mathrm{mg} / \mathrm{Kg})$ which completely blocked cardiohemodynamic effects of $1 \mu \mathrm{g} / \mathrm{Kg}$ of norepinephrine, markedly attenuated the effects of perhexiline on VR and PAF but not completely. It is concluded that the effect of perhexiline to increase VR and PAF is in most part mediated through the cardiovascular reflex control for blood pressure reduction by the drug, though a direct effect on capacitance vessels may be included.

\section{Additional Indexing Words:}

Venous return Cardiac output Circulatory reflex Vasodilators

$I^{\mathrm{T}}$

$T$ is indispensable for appraisal of a vasodilator drug in clinical use to examine its effects on the hemodynamics. Antianginal effect of glyceryl trinitrate (nitroglycerin) is partly attributed to its action on hemodynamics. ${ }^{1 \prime}$ Glyceryl trinitrate has been known to reduce preload to the heart, i.e. venous return ${ }^{2}$ besides its effect of reducing the afterload i.e. peripheral vascular resistance. This sequence has led to the conception of unloading therapy of heart failure with vasodilator drugs. ${ }^{3)}$ On the other hand, vasodilators may cause a drastic hypotension by an excessive use, by the effect on peripheral vasculature, as is often the case, combined with cardiodepressant effect. Moreover, Kokubun et $\mathrm{al}^{4)}$ and Imai et $\mathrm{al}^{5)}$ showed that various

From the Hatano Research Institute, Food and Drug Safety Center, Hadano, Kanagawa, Japan. Received for publication August 18, 1980.

Manuscript revised October 18, 1980. 
calcium antagonistic vasodilators, dilazep, diltiazem, D 600, nifedipine, prenylamine, SK \& F 24260, and trimethazidine, increased venous return (VR) and cardiac output of anesthetized dogs except at excessive doses which caused obvious cardiac depression.

Perhexiline, 2-(2,2-dicyclohexylethyl)piperidine, is a recently developed vasodilator that has been reported useful in treatment of angina pectoris $^{6)}$ and that is classified in calcium antagonists. ${ }^{7)}$ We have studied the pharmacology of perhexiline and have reported some interesting features of it. ${ }^{8)-12)}$ In this paper we describe the cardiohemodynamic effects of perhexiline in anesthetized open-chest dogs including some analyses of the effects.

\section{Methods}

Experiments were carried out essentially according to the methods of Kokubun et al.4) Mongrel dogs of either sex weighing $8.5-12.5 \mathrm{Kg}$ were anesthetized with intravenous pentobarbital sodium initially of $30 \mathrm{mg} / \mathrm{Kg}$ and subsequently with hourly supplement of $3-5 \mathrm{mg} / \mathrm{Kg}$ to maintain an adequate level of anesthesia. Mechanical respiration was performed with a Harvard respirator through the intubated trachea. Thorax was opened by mid-sternotomy and the heart was positioned in the pericardial cradle. Probes of non-cannulating type for electromagnetic flowmeters (Narco, RT500) were attached to the superior and inferior venae cavae and to the pulmonary trunk. The azygos vein was ligated. Interactions among these flowmeters were minimized by adjusting the phase of magnetizing current through the three flowmeters. Right atrial pressure was measured by a cannula inserted into the auricle with a pressure transducer (Statham, P23BB) and systemic blood pressure at the femoral artery with a Statham P23Db transducer through carrier amplifiers (San-ei Sokki, 1206B) assembled in a polygraph (San-ei Sokki, 142-8). Heart rate was measured from ECG with a tachometer (DataGraph, T-149) which displayed the rate per minute beat by beat digitally and put out analog signals for the recorder. These parameters were recorded on inkwriting rectilinear recorders (San-ei Sokki, Recti-Horiz 8S-53).

Drugs used in this study were: 1-norepinephrine (Fluka), perhexiline hydrochloride (Merrell), phentolamine mesylate (Ciba), dl-propranolol hydrochloride (Sigma), and dl-verapamil hydrochloride (Eisai). Perhexiline and verapamil were dissolved in distilled water and injected slowly over $2 \mathrm{~min}$, to avoid drastic effects by a bolus injection. ${ }^{8)}$ All the doses refer to their bases. Statistical analyses were made according to Student's t-test.

\section{Results}

Three electromagnetic flowmeters, probes of which were in close proximity interacted on each other to alter the measurements by up to $5 \%$, even though the interactions were minimized as described in Methods. 
The right ventricular output or the blood flow rate of the pulmonary artery (PAF), however, showed fairly good accordance with the venous return (VR) or the sum of blood flow rates of the superior and inferior venae cavae. Mean control PAF of 13 animals was $756 \pm 41 \mathrm{ml} / \mathrm{min}$ and VR was $689 \pm 75$ $\mathrm{ml} / \mathrm{min}$ in the beginning of the measurements. As the experiments proceeded, however, both values tended to decline and the discrepancy between these two values enlarged perhaps from impairment of tight contact of a flowmeter probe to the vessel wall.

Intravenous administration of $0.3-3 \mathrm{mg} / \mathrm{Kg}$ of perhexiline increased PAF and VR in a tolerably dose-dependent manner. Increases in PAF and VR were in good temporal correlation, both had the peak at 2-3 min from the initiation of injection and returned to the control level within 5-6 min and then usually showed decreases. Extent of increases in PAF and VR was not so remarkable and reached about $20 \%$ with $3 \mathrm{mg} / \mathrm{Kg}$ of perhexiline. Systemic blood pressure (SBP) and heart rate (HR) decreased with perhexiline dose-dependently, though in a few cases slight increases intervened. Right atrial pressure (RAP) was increased with perhexiline. A typical experimental record is illustrated in Fig. 1 and the summarized data are shown in Fig. 2.

Verapamil, $0.03-0.3 \mathrm{mg} / \mathrm{Kg}$ injected over $2 \mathrm{~min}$, initially increased and later decreased RAF and VR. Dose-dependency in these effects was not plain as decreases became greater than increases with the higher dose. SBP and HR uniformly decreased and RAP increased with verapamil

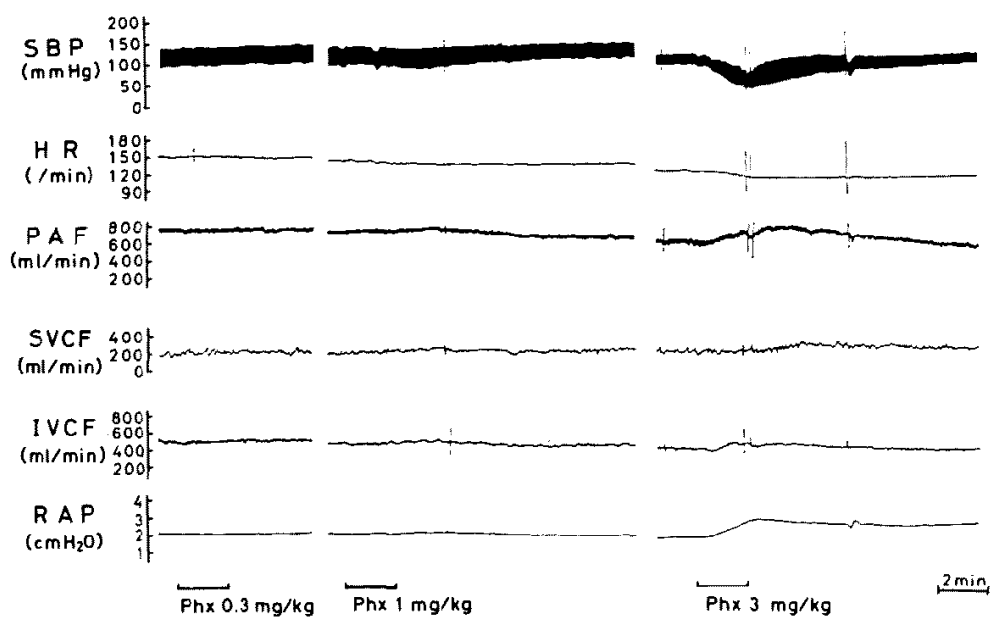

Fig. 1. Typical responses to intravenous perhexiline $(\mathrm{Phx})$ of the systemic blood pressure (SBP), heart rate (HR), pulmonary arterial blood flow (PAF), blood flow rates of superior vena cava (SVCF) and inferior vena cava (IVCF), and right atrial pressure (RAP) in an anesthetized open-chest dog. 


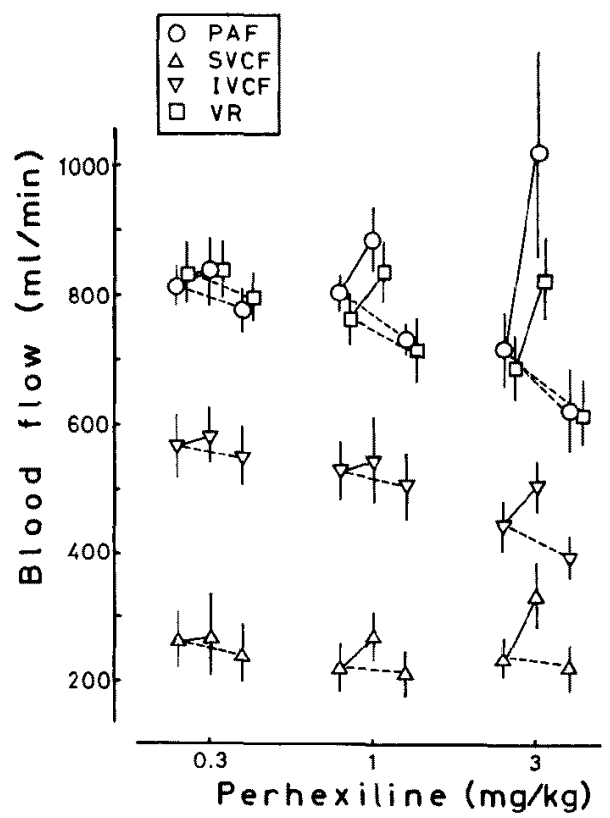

(a)

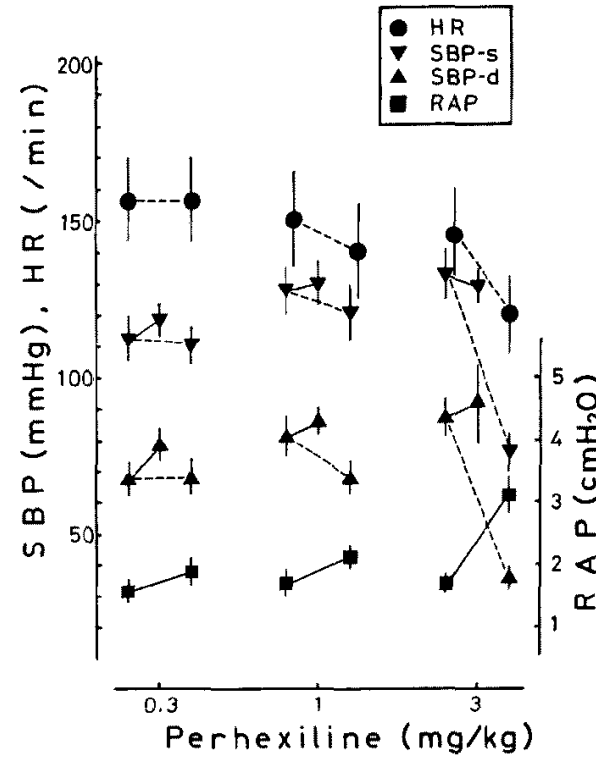

(b)

Fig. 2. (a) Changes of blood flow rates through the pulmonary artery $(O, P A F)$, superior $(\triangle, S V C F)$ and inferior vena cava $(\nabla$, IVCF $)$, and those of venous return $(\square, V R)$ induced with perhexiline. Peak changes of increases and decreases were separately gathered.

(b) Changes of heart rate $(\boldsymbol{O}, \mathrm{HR})$, systolic ( $\boldsymbol{\nabla}, \mathrm{SBP}-\mathrm{s})$ and diastolic blood pressure $(\boldsymbol{\Lambda}, \mathrm{SBP}-\mathrm{d})$, and right atrial pressure $(\boldsymbol{\boldsymbol { O }}, \mathrm{RAP})$ induced with perhexiline. Increases and decreases were separately gathered for blood pressure changes. Vertical bars indicate standard errors. $\mathrm{N}=5$.

dose-dependently. A typical experiment is shown in Fig. 3.

Effects of autonomic blockade on the hemodynamic effects of perhexiline were analyzed and shown in Fig. 4. Treatment with $1 \mathrm{mg} / \mathrm{Kg}$ of propranolol decreased PAF (by 18\%), SBP (by 17\%), HR (by $26 \%$ ), and VR (by $36 \%$ ), and increased RAP (by 90\%). Effects of norepinephrine on PAF and HR were blocked by propranolol and these showed steep decreases secondary to an increase of SBP. Increase of VR with $1 \mu \mathrm{g} / \mathrm{Kg}$ of norepinephrine was not blocked by $1 \mathrm{mg} / \mathrm{Kg}$ of propranolol, though it was somewhat attenuated. Effects of perhexiline to increase VR and PAF were not blocked with the propranolol treatment. Intravenous phentolamine, $1 \mathrm{mg} / \mathrm{Kg}$, administered to the dog pretreated with propranolol, further decreased SBP (by $26 \%$ ) and HR (by 7\%), also decreased VR (by 16\%), PAF (by 16\%), and RAP (by 21\%) after short-lasting increases, and completely blocked the cardiovascular effect of $1 \mu \mathrm{g} / \mathrm{Kg}$ of norepinephrine. The effects of 

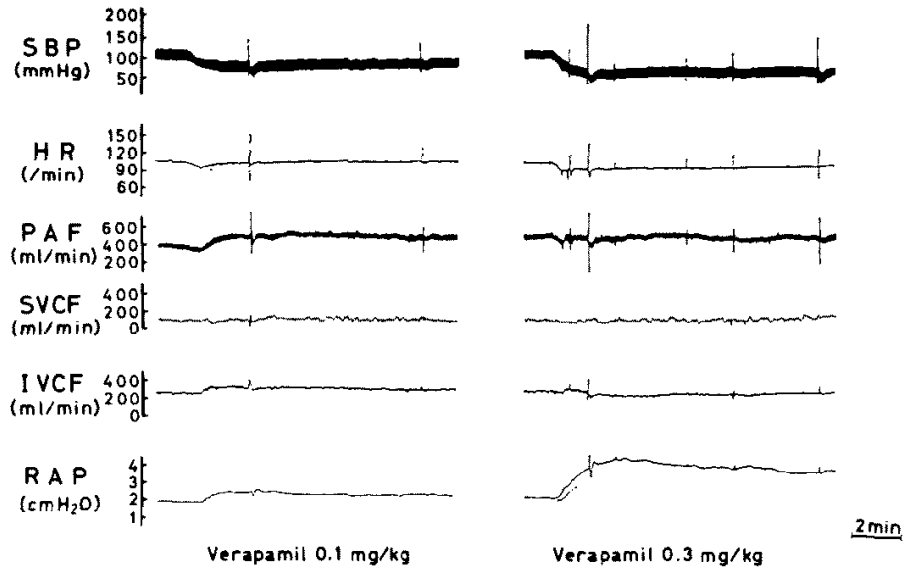

Fig. 3. Cardiohemodynamic effect of verapamil showing increases in venous return (SVCF and IVCF) and pulmonary blood flow (PAF). The abbreviations are the same as in Fig. 1.

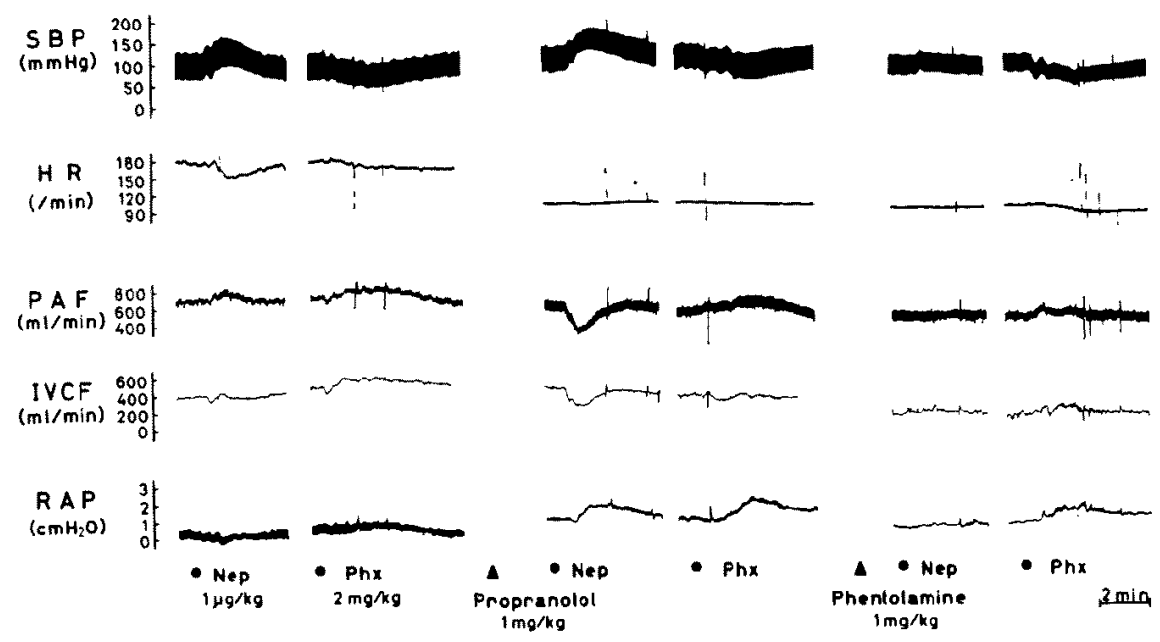

Fig. 4. Effects of adrenergic blockade on the cardiohemodynamic effects of perhexiline, compared with those of norepinephrine (Nep). Other abbreviations are the same as in Fig. 1. Records of superior vena caval flow are omitted in this figure because of simplification.

perhexiline on VR and PAF, however, were not completely blocked by these treatments with propranolol and phentolamine.

\section{Discussion}

While measurements of left heart performance and the consequences in systemic circulation are relatively abundant in the study of hemodynamics, 
either clinical or experimental, investigations on the venous return are scanty. Kokubun et $\mathrm{al}^{4)}$ measured the venous return as the sum of blood flow rates through the superior and inferior venae cavae in open-chest dogs anesthetized with pentobarbital. Although the inevitable procedures, anesthesia, positive pressure breathing, and thoracotomy, must have some influence on the normal state of the venous return, this is a useful method in experimental evaluation of the hemodynamics. Kokubun et al $^{4}$ ' showed a clear-cut difference between nitroglycerin and other vasodilators in cardiohemodynamic effects; nitroglycerin decreased venous return and right atrial pressure while other kinds of vasodilators, especially $\mathrm{Ca}^{2+}$-antagonistic coronary dilators such as etafenone, nifedipine, and prenylamine, increased venous return and right atrial pressure, though another $\mathrm{Ca}^{2+}$-antagonist iproveratril (verapamil) decreased venous return. In the succeeding study, ${ }^{5)}$ they investigated further the cardiohemodynamic effects of other $\mathrm{Ca}^{2+}$-antagonistic vasodilators, D 600, dilazep, diltiazem, SK \& F 24260, and trimethazidine and obtained a common pharmacological feature of these drugs that they produced slight increases followed by decreases in venous return and cardiac output except for SK \& F 24260 which markedly increased them.

Perhexiline has been classified as a $\mathrm{Ca}^{2+}$-antagonist by FleckensteinGrün et $\mathrm{al}^{\text {7) }}$ by the fact that it inhibited excitation-contraction coupling in guinea pig papillary muscle, which was antagonized by addition of excess $\mathrm{Ca}^{2+}$ in the medium. Observations of our $\mathrm{own}^{91,12)}$ are substantially in agreement with this proposal. In the present study perhexiline showed hemodynamic effects which were in accordance with above mentioned $\mathrm{Ca}^{2+}$ antagonistic vasodilators. We also observed that verapamil did increase venous return and pulmonary arterial flow to a limited extent. Although in the study of Kokubun et al $^{4}$ verapamil was reported to decrease venous return and cardiac output, Taira et al $^{\mathbf{1 3})}$ showed that verapamil increased venous return in the dog with open-loop method, in which the blood flow of both the venae cavae were drained and pumped back to the right atrium at a constant rate, i.e. the input to the heart was kept constant. It is considered that verapamil has a feature common to other $\mathrm{Ca}^{2+}$-antagonists to increase venous return in a dose range it does not depress cardiac function so much.

Mechanism of action of perhexiline and other $\mathrm{Ca}^{2+}$-antagonistic vasodilators of this kind to increase venous return was analyzed by adrenergic blocking agents, because one most probable mechanism was autonomic cardiovascular reflex activated by blood pressure decrease produced with the drug. Propranolol enough to antagonize $\beta$-adrenergic action of $1 \mu \mathrm{g} / \mathrm{Kg}$ of norepinephrine could not block the increase in venous return with $2 \mathrm{mg} / \mathrm{Kg}$ of 
perhexiline. Imai et al ${ }^{14}$ emphasized $\beta$-adrenergic mechanism in increase of venous return by norepinephrine and almost excluded the contribution of $\alpha$ adrenergic mechanism from their results with open-loop method that propranolol blocked increase of venous return by norepinephrine and that methoxamine failed to increase venous return. In the present study, norepinephrine administered to a propranolol-treated animal produced predominant blood pressure increase through constriction of peripheral arteries resulting in steep increase in the afterload on the heart which might severely depress cardiac output especially in a failing heart. Decrease in cardiac output prohibits venous return to increase. In the present experiment perhexiline still increased pulmonary arterial flow in propranololtreated $\operatorname{dog}$ and this effect was inhibited with phentolamine treatment, though the difference of these values were not statistically significant. We hold that the $\alpha$-adrenergic mechanism controlling peripheral vascular capacitance participates in increase of venous return with perhexiline as well as the possible $\beta$-adrenergic mechanism on the venous resistance as evidenced by Green ${ }^{15)}$ and supported by Imai et al. ${ }^{14}$ ) The additive treatment with propranolol and phentolamine, though the effect of norepinephrine was almost completely antagonized, could not inhibit completely the increase of venous return caused by perhexiline. Thus, increase in venous return with perhexiline is considered to be due in the most part to reflex sympathetic drive but in some extent, to a direct action of the drug on the capacitance vessel or on the venous resistance.

Increase of pulmonary arterial flow with perhexiline is explained by increase of venous return. A slight increase in systemic cardiac output was also observed when aortic blood flow was measured (unpublished observation). A slight positive inotropic action was observed with relatively low doses of perhexiline in a papillary muscle preparation of the dog perfused with blood.9' This action may also participate in its effect in increasing cardiac output.

In summary, perhexiline increased venous return and pulmonary arterial flow or cardiac output through the cardiovascular reflex mechanism activated by blood pressure decrease and through its direct action probably on venous resistance. Although the significance of these properties in clinical usage is beyond the scope of this study, it can be pointed out that a drastic change in blood pressure and heart rate will not occur with administration of perhexiline by oral route and that a hypotensive effect of the drug through vasodilation will be compensated to some extent by an increase of the venous return. 


\section{References}

1. Nickerson M: Vasodilator drugs, in The Pharmacological Basis of Therapeutics, 5th Ed, ed by Goodman LS, Gilman A, Macmillan, New York, p. 727, 1975

2. Ogilvie RI: Effect of nitroglycerin on peripheral blood flow distribution and venous return. J Pharmacol Exp Ther 207: 372, 1978

3. Miller RR, Vismara LA, Williams DO, Amsterdam EA, Mason DT: Pharmacological mechanisms for left ventricular unloading in clinical congestive heart failure. Circulat Res 39 : 127,1976

4. Kokubun M, Taira N, Hashimoto K: Cardiohemodynamic effects of nitroglycerin and sevcral vasodilators. Jpn Heart J 15: 126, 1974

5. Imai Y, Himori N, Taira N: Cardiohemodynamic effects of SK \& F 24260, diltiazem, dilazep, and trimetazidine in the dog. Jpn Heart J 18: 120, 1977

6. Ferlmann $\mathrm{H}_{-}$, Krehan L, Kaltenbach M: Wirkung von Perhexilinmaleat auf BelastungsEkg von Patienten mit koronarer Herzerkrankung. Z Kardiol 68: 826, 1979

7. Fleckenstein-Grün G, Fleckenstein A, Byon YK, Kim KW: Mechanism of action of $\mathrm{Ca}^{2+}$ antagonists in the treatment of coronary disease with special reference to perhexiline maleate. in Perhexiline Maleate, Excerpta Medica, Amsterdam, p. 1, 1978

8. Ono H, O'Hara N, Oguro K: Difference in the responses to perhexiline induced by the different concentrations of solution administered intravenously in anesthetized dogs. Pharmacometrics (Oyo Yakuri) 18: 767, 1979

9. Ono $\mathrm{H}$, Hashimoto $\mathrm{K}$ : $\mathrm{Ca}^{++}$antagonism in various parameters of cardiac function including coronary dilatation with the use of nifedipine, perhexiline, and verapamil. in Ischemic Myocardium and Antianginal Drugs, ed by Winbury MM, Abiko Y, Raven Press, New York, p. 77,1979

10. Ono $\mathrm{H}$, Kimura $\mathrm{M}$ : Effect of $\mathrm{Ca}^{2+}$-antagonistic vasodilators, diltiazem, nifedipine, perhexiline and verapamil on platelet aggregation in vitro. Arzneimittelforsch 31: 1131, 1981

11. Oguro $\mathrm{K}$, Ono $\mathrm{H}$ : Effects of perhexiline on contractile response of rabbit aorta to norepinephrine and potassium. Eur J Pharmacol 68: 61, 1980

12. O'Hara $\mathrm{N}$, Ono $\mathrm{H}$, Oguro $\mathrm{K}$, Hashimoto $\mathrm{K}$ : Comparative study of vasodilating effects of perhexiline, glyceryl trinitrate and verapamil on coronary, femoral, mesenteric and renal vascular beds in the dog. J Cardiovasc Pharmacol 3: 251, 1981

13. Taira N, Imai Y, Hiwatari M: Differential effects of nitroglycerin, trimetazidine, verapamil and SK \& F 24260 on venous return as revealed by the open-loop method in the dog. Jap J Pharmacol 30:449, 1980

14. Imai $\mathrm{Y}$, Sato $\mathrm{K}$, Taira $\mathrm{N}$ : Role of the peripheral vasculature in changes in venous return caused by isoproterenol, norepinephrine, and methoxamine in anesthetized dogs. Circulat Res 43: 553, 1978

15. Green JF: Mechanism of action of isoproterenol on venous return. Am J Physiol 232: H152, 1977 